\title{
Characterization of Best Practices for Customer/Supplier Collaboration in Co-innovation Projects
}

\author{
Carlos Abraham Moya ${ }^{1 *}$, Vincent Boly ${ }^{1}$, Laure Morel $^{1}$, Daniel Gálvez ${ }^{2}$, Mauricio Camargo ${ }^{1}$
}

\begin{abstract}
High market competitiveness and a lack of internal resources and knowledge make companies increasingly interested in open innovation, being the collaborative innovation projects with suppliers one of the most widely used initiatives. However, the collaborative process is difficult to manage given the diversity of factors to consider when mixing different organizational cultures, resources, competencies, and experiences. One way to support the process is through the management of related good practices. Therefore, based on a review of the literature and international standards on open innovation or collaboration, this document identifies five dimensions and 18 practices of the customer-supplier collaborative innovation process. The identification of these good practices allows the characterization of the customer/supplier collaboration process in innovation projects and allows the establishment of a reference framework for the creation of an evaluation model.
\end{abstract}

Keywords: co-innovation; framework; customer/supplier collaboration; best practices.

Submitted: April 21 $1^{\text {st }}, 2020 /$ Approved: December $18^{\text {th }}, 2020$

\section{Introduction}

In an increasingly competitive context, new product development is critical to the survival of companies. At the same time, they face internal shortcomings and resource shortages (Wang \& Kourouklis, 2012)they need to embrace open innovation strategies. Subsequently, involving suppliers and customers into the process of NPD has been viewed as the most effective means by which internal and external knowledge resources can be optimally leveraged. However, there is a lack of available and reliable mechanisms to facilitate this process. This paper presents a comprehensive theoretical framework developed by harmoniously combining the relevant theoretical fields of Knowledge Management (KM. Under these circumstances, companies try to maintain their competitive advantage through different strategies. One of the current strategies is to open their borders to the external flow of skills, knowledge, and technologies, a strategy that is widely known in the literature as Open Innovation ( $\mathrm{H}$ W Chesbrough, 2003 ; Henry William Chesbrough, 2006).

Despite the diversity of possible partners, one of the most common relationships that companies have is with their suppliers, in the context of collaborative innovation. Indeed, working with suppliers on innovation projects has several benefits; it improves project success and leads to execution time and cost reductions, as well as to quality enhancement, but also allows access to new products, skills, and key technologies (Clauß, 2012 ; Rémi Maniak, Midler, Beaume, \& von Pechmann, 2014). On the other hand, it represents a great organizational and managerial challenge for companies, given the diversity of factors to consider when mixing different cultures, different resources, competencies, and procedures (Rosell \& Lakemond, 2012). Therefore, in collaborative innovation, not only technical skills matter, but also soft aspects including trust, cultural compatibility, and relational aspects (Le Dain, Calvi, \& Cheriti, 2011 ; Patrucco, Luzzini, \& Ronchi, 2017 ; Tello Gamarra, Machado Leo, Silva Avila, \& Wendland, 2018). Collaboration means a close and intensive exchange between people from different entities. This research addresses a better understanding of activities shared by all stakeholders at a micro level. Hypothesizing that collaboration is a temporary working space common to two entities, the aim is to list a set of best practices highly specific to an innovation process built up by two collaborating structures. As the attention of more and more customers and suppliers is directed toward the improvement of the dynamics of collaborative innovation, our contribution consists in proposing a new activities' referential for any collaboration. It is represented as a multidimensional process, meaning a sequences of tasks aiming a particular result, that can be managed and improved (de Soria, Alonso, Orue-Echevarria, \& Vergara, 2009). Note that it is difficult to manage or improve a process without evaluating it (Boly, Camargo, \& Morel, 2016); consequently, the outcomes of this research may help define a metric for the innovation collaboration process.

The set of identified good practices will also allow the establishment of a structure for the evaluation of the customer/supplier collaboration. Therefore, the aim of this document is both to define a reference framework, or the structure of an evaluation model, and to identify its corresponding good practices. The research focuses on a pairwise collaboration, even if many collaborative innovation projects involved more than two partners.

To this end, the first step is to search and review international standards on collaborative or open innovation. By means of this review of documents, the existing standards, models, and frameworks were compared and analyzed to elaborate a framework that enables the description and/or evaluation of the process of collaboration between the two companies. In conclusion, it was possible to identify five dimensions and a group of practices associated with the customer/ supplier collaboration in an innovation project. The five dimensions are strategy, organizational, operational, ecosystem, and human. Each dimension represents a different point of view of the collaboration relationship.

1) Equipe de Recherche sur les Processus Innovatifs (ERPI), Université de Lorraine, 8 rue Bastien Lepage 54010 Nancy Cedex - France

2) Departamento de Ingeniería Industrial, Universidad de Santiago de Chile, Av. Ecuador 3769 Santiago Chile

${ }^{*}$ Corresponding author: moyaseda1@univ-lorraine.fr

ISSN: 0718-2724. (http://jotmi.org)

Journal of Technology Management \& Innovation (c) Universidad Alberto Hurtado, Facultad de Economía y Negocios. 
The remainder of this article is organized according to three sections. First, an overview of customer/supplier collaboration is given. This is followed by the definition of dimensions and practices through the review of the ISO, CEN, and AFNOR standards on open innovation or collaboration and the international literature on models and frameworks of co-innovation. Finally, conclusions and perspectives are detailed.

\section{Overview of the customer/supplier collaboration concept}

In this chapter, the definitions, benefits, and key success factors of a customer/supplier collaborative innovation are detailed.

\section{Co-innovation definition}

Different concepts, such as collaboration, partnerships, or cooperation, characterize the innovation process between customer and supplier. Thus, the definition provided by the OECD for collaboration through the Oslo Manual (OECD, 2019)243000 (0.000002\% is as follows: "Collaboration requires co-ordinated activity across different parties to address a jointly defined problem, with all partners contributing. Collaboration requires the explicit definition of common objectives and it may include agreement over the distribution of inputs, risks and potential benefits. Collaboration can create new knowledge, but it does not need to result in an innovation. Each partner in a collaboration agreement can use the resulting knowledge for different purposes." According to this definition, collaboration does not necessarily result in innovation, but the same document argues that when collaboration outcomes are innovative, it is called co-innovation. This is the theoretical background adopted for this research.

Co-operation is another concept where there is no initial definition of a common problem and objective as in the case of collaboration. In the case of partnerships, it is the contractual framework or the agreement between actors. A collaboration does not always imply a partnership. The essence of an innovation partnership is that all actors benefit mutually from collaboration (ISO, 2019).

\section{Co-innovation benefits between customers and suppliers}

More and more organizations are deciding to adopt innovation strategies but face a lack of internal resources (Littler, Leverick, \& Bruce, 1995 ; Vega-Jurado, Juliao-Esparragoza, Paternina-Arboleda, \& Velez, 2015 ; X. Zhang, 2016). For this reason, companies look to their ecosystem for getting the necessary resources, knowledge, technologies, and expertise (Knoke, Missikoff, \& Thoben, 2015 ; Radziwon \& Bogers, 2019). Despite the diversity of stakeholders in the ecosystem, one of the most commonly observed relationships remains the collaboration between companies and their suppliers. The customer/ supplier relationship therefore becomes a major research concern.

A particular case of customer/supplier relationships is collaboration on the development of an innovation project. Known as co-innovation (H. Chesbrough \& Bogers, 2014) or collaborative innovation, this initiative is a particular case of partnership in the context of open innovation, reserved for two partners who have the objective to develop a joint innovation project.
In a collaborative process, enterprises link their activities, combine resources (Laursen \& Andersen, 2016), leverage external knowledge, and create value through interaction. In this case, suppliers allow companies to complete the internal knowledge base with external information (Rosell \& Lakemond, 2012), because they cannot keep their technology up to date (A. K. W. Lau, Lee, Lai, \& Lee, 2018). Suppliers are often the source of new technologies and specific knowledge for companies as they master key technologies (Rémi Maniak et al., 2014). Consequently, some authors argue that closing in on a group of historical suppliers is not a good practice because it limits the possibilities of capturing the signals of new trends in an industrial context (Lavastre, Carbone, \& Ageron, 2016).

Other benefits of supplier integration include a shortening of the time to market (Bengtsson, Lakemond, \& Dabhilkar, 2013 ; Y. Zhang, Wang, \& Gao, 2017), reduction of development and product costs (Ragatz, Handfield, \& Scannell, 1997 ; Sjoerdsma \& van Weele, 2015 ; Wynstra \& Pierick, 2000), more innovative and higher-quality products (Bengtsson et al., 2013), better operating margins, and more innovations (Fossas-olalla, Lopez-sanchez, \& Minguela-rata, 2010). In the case of customer-supplier collaboration, partners have access to different knowledge. Thus the customer benefits from an intermediary position between the target market and the suppliers. Therefore, the customer knows the different suppliers but also the consumer's needs. In contrast, suppliers know the competitors of a manufacturing customer, but usually have no direct relationship with the market (Sariola, 2018). In this way, innovation project ideas can come from different sources, upstream or downstream in the value chain. So companies must develop the skills to understand their customers' needs, and at the same time, the ability to work with their suppliers. Relational capabilities (Melander, 2018) and capabilities to identify and integrate innovative suppliers with unique assets, technologies and resources represent key success factors (Bengtsson et al., 2013 ; Sjoerdsma \& van Weele, 2015 ; Soosay, Hyland, \& Ferrer, 2008).

\section{Co-innovation key success factors}

Innovative collaboration success is dependent upon several variables. An initial factor widely studied in the literature and considered important is absorption capacity, understood as the capability to capture, manage, and integrate external knowledge (Pihlajamaa, Kaipia, Säilä, \& Tanskanen, 2017 ; Un, 2017)or investments in R\&D purchased from external providers. I build on the knowledge-based view of the firm (KBV. Collaboration also depends on skills in the use of interactive tools within the design team. This includes communication and information technologies, as well as Virtual Reality.

Authors also cite certain sociological variables, including trust. This factor is related to the assurance that the other company will deliver on its commitments and that it will not take advantage of its partner's weaknesses (Dung, 2015 ; Hasche, Linton, \& Öberg, 2017 ; Hudnurkar, Jakhar, \& Rathod, 2014 ; Su, Song, Li, \& Dang, 2008). Trust is built through different phenomena, such as the fulfillment of supply contracts, the partner's reputation (Kwon, Louis, \& Louis, 2004), bargaining power, commitment (Schiele, Veldman, \& Hûttinger, 2011), 
etc. It is therefore considered a factor that is generated through the historical antecedents of the relationship and consequently is a factor developed in the long term.

Co-innovation is a collaborative strategy where partners have common objectives and seek mutual benefits. Common objectives must be congruent with each partner's strategy, because companies seek to foster their own objectives through the objectives of the collaboration (de Paulo, De Oliveira, \& Porto, 2017 ; Hudnurkar et al., 2014). In addition to the common objectives and strategies, collaborating companies establish the allocation of both financial and material resources and the mutual investment to be made (Bhaskaran \& Krishnan, 2009 ; Melander, 2018). This allocation of resources and investment may not be equal between the companies, nor the distribution of created value and profits.

Also, the collaborative process involves different changes that can generate a natural resistance which can hinder the innovation project. An example of resistance is the phenomenon "not invented here" which is the rejection of ideas coming from outside (Greco, Grimaldi, \& Cricelli, 2019 ; Herzog \& Leker, 2010 ; Ragatz, Handfield, \& Scannell, 2003). Thus, change management and conflict resolution skills are important in the collaborative process.

In addition, the customer/supplier collaborative process is linked to the adoption of a new organization. Thus an important competence is the ability to manage the interface between the two companies. In the customer/supplier relationship, the customer's purchasing department is often nominated to handle the interface between the two companies (Luzzini, Amann, Caniato, Essig, \& Ronchi, 2015 ; Patrucco et al., 2017 ; Servajean-Hilst \& Calvi, 2018). This organizational function, which evolves into a strategic function, is perfectly positioned to identify and capture external opportunities (Maier, Rück, \& Brem, 2017). It can therefore play an active role in exploiting sourcing opportunities (Legenvre \& Gualandris, 2018) and contributing to new product development (Schiele, 2010), without neglecting its task in cost management.

From the literature, it is possible to demonstrate the different benefits of collaboration between the customer and supplier in an innovation project, but it is also possible to verify that it is not an easy strategy to implement. Through collaboration, companies work together and must therefore combine their culture, strategy, resources, and organizational structure (Fielke et al., 2018 ; Herzog \& Leker, 2010). Thus each collaboration is specific due to the sequence of tasks in the process of collaboration, the characteristics of the relationship between the two companies, and the characteristics of the innovation project. In summarizing all the above elements, it can be observed that innovation collaboration is a complex process. This motivates the customer and supplier to try to improve the dynamics of collaborative innovation (de Soria et al., 2009). These dynamics evolve over time and subsequently require permanent supervision and adjustment, and consequently an evaluation process.

In the context of innovation management and adopting a systemic approach, (Boly et al., 2016) suggest that the evaluation of the innovation process should not be done at the level of resources or results, but at the level of practices and activities of the process. The assessment of results and resources in regard to innovation is interesting but also attests to serious limitations when elaborating a metric: uncertainty severely restricts the correlation between the characteristics of the project (activities), the means mobilized (resources), and the outcomes (results such as patents and value creation). Therefore, analogous to innovation, in order to better describe in situ phenomena of customer/supplier collaboration in innovation projects, practices associated with the process must be identified. Thus this research seeks to propose a new framework for collaboration and to detail it through a list of practices extracted from the literature. The model supported by the list of referential practices will help to describe the phenomena observed during the collaboration, to allow a comparison between projects, and to elaborate a metric in the future.

\section{Method}

In order to contribute to the modeling of the collaborative innovation process between the customer and supplier, the objective of this document is to define a reference framework and the basis of the structure of an evaluation model based on good practices.

Figure 1. Research Methodology

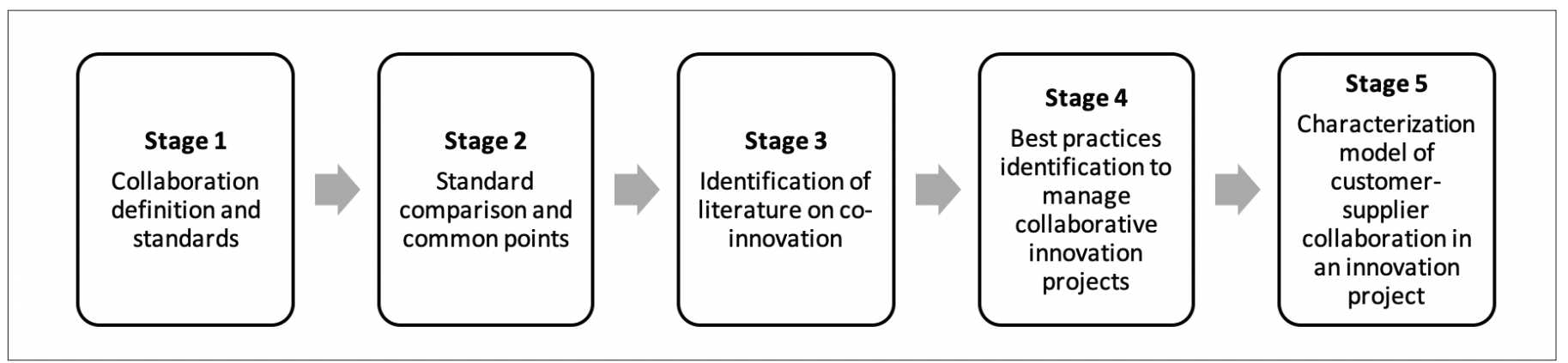

Therefore, a five-stage methodology was followed (See Figure 1). The first stage is the identification of standards linked to collaborative innovation projects. The second stage is the analysis and comparison of the ISO, CEN, and AFNOR standards identified. The two preceding stages allow us to define a normative framework of five-dimensional collaborative projects. The third stage is the review of literature on co-innovation models and frameworks. Stage 4 is the identification of good practices to manage collaborative innovation projects between 
the customer and supplier. The aim is to compare the conclusions of the standards analysis with the frameworks and models found in the literature review. Finally, Stage 5 proposes a model for characterizing collaboration between the customer and supplier in an innovation project.

\section{Stage 1: Collaboration and standards}

In an open innovation context, where companies are willing to open their boundaries to information flows and to create alliances/partnerships with the members of their ecosystem, collaboration represents a particular case. This relationship has been extensively studied in the international literature; from different points of view, however, some limitations remain for the detailed description of collaborative innovation phenomena. For this reason, the research is oriented toward the review of documents such as ISO, CEN, and AFNOR standards, which are built based on experts' and practitioners' agreements and which provide recommendations for the management of collaboration. The analysis focuses on defining coinnovation and key factors for the success of a partnership. The documents studied are ISO 56002 (ISO, 2019), FD X50-272 (AFNOR, 2019), and XP CEN/TS 16555 in Part 5 (CEN, 2014). The search for standards was carried out on the $\mathrm{SAGAWEB}^{\circ}$ platform.

\section{ISO 56002 "Innovation management-Innovation management system-Guidance"}

The international standard ISO 56002, published in 2019, presents recommendations about implementing and managing an innovation management system. Its objective is to guide organizations on the different elements that compose the innovation management system.

The different components of the innovation management system are leadership, operations, performance evaluation, improvement, planning, support, and finally the context of the organization. In this system, collaboration is considered in the context of the organization together with culture and internal or external issues.

ISO 56002 refers to the benefits or objectives of internal and external collaboration, such as access to knowledge, skills, infrastructure, markets, assets, and resources. As a suggestion, the standard recommends that organizations consider the innovation and collaboration strategy, existing competencies, different methods and agreements for external collaboration, intellectual property issues, and the culture of respect, openness, and trust between the parties.

\section{CEN/TS 16555-5 "Innovation Management"}

Presented in 2015, this European standard is divided into seven parts under the concept of innovation management. Part 5 deals specifically with collaboration management. This section presents guidelines for the management of collaboration between people, services, or companies. The recommendations are even applicable to all types of organizations committed to innovation, with special attention given to SMEs.

The guidelines address when, how, and with whom to collaborate, the benefits and difficulties. Some elements are highlighted that allow the generation of new ideas and of value: sharing costs and risks, new competencies, complementary expertise, experience, technologies, and resources.

This standard points out different types of possible partners and suggests giving attention to the choice of a suitable partner and a suitable form of collaboration (internal, bilateral, consortium, or open innovation). Factors mentioned in the standard CEN/TS 16555-5 to be considered when choosing a partner are the difference in size between the companies, the stage of the innovation process in which the collaboration is involved, and the geographical distance between the partners.

\section{FD X50-272 "Management of Innovation-Guidelines for imple- menting an open innovation approach"}

The standard proposed by the French Association for Standardization (AFNOR) addresses the management of innovation to give recommendations about the implementation of an open innovation approach in all types of organizations and sectors of activity. This standard contains a detailed description of the organization's ecosystem, arguing that open innovation is a source of value creation.

Interactions in open innovation can be classified according to the degree of openness with participants and the mode of operation. Under these criteria, a matrix is generated where four types of situations are recognized: know-how search (e.g. technology platforms), intermediation (e.g. outsourcing), innovation networks (e.g. crowdsourcing), and collaborative innovation (e.g. co-innovation). However, there are intermediate situations where organizations seek to organize their network to improve their offer. Each of the situations involves different interactions with one or many actors, different exchanges of information, governance, and intellectual property, among other things.

This guide distinguishes a strategic and an operational level of the innovation process. At the strategic level, four stages are addressed: exploration, evaluation and decision, project management, and capitalization. In addition, collective commitment of the partners, identification of partners in coherence with the strategy of the organization, definition of a method of governance and contractualization of the collaboration, project management, communication techniques, and distance work constitute key success factors.

\section{Stage 2: Standard comparison and common points}

By comparing the three revised standards, it is possible to identify some differences related to the origin of the standard (International, European, or French), the objective of the standard, and how deeply the concept of collaboration is treated, among other things.

ISO 56002 is an internationally accepted standard and the most current for its recent publication in 2019 and its content discusses recommendations for the management of an innovation system, where collaboration is part of the context. On the other hand, the European standard on innovation management offers one of its parts specifically for collaboration management, giving different recommendations according to different criteria (stage of the process, size of companies, etc.). 
At the French level, until 2014 the FD X50-272 standard appeared as the first standardization work on the implementation of open innovation, where collaborative innovation is contained as one of the four possible scenarios. Therefore, regarding collaboration, the ISO standard will give more general recommendations, while the French and European standards are more specific.

Despite observable differences, it is possible to identify similarities between the three standards concerning the definition of collaboration and recommendations for its management. Five common aspects are identified in the different documents:

- Objectives (strategy): A common element is the explicit definition of a common strategy and/or objectives, which include how the inputs and outputs of the collaboration will be distributed. For this definition, organizations should be aware of existing resources, capabilities, and skills. The agreements on the intellectual property that each participant contributes and also that which will be generated during the collaboration should be reviewed. In addition, there must be a definition of the methods, rules, and governance that will guide the collaborative process. Agreements on the responsibilities and roles of each partner are required.

- Process activities (operational): The collaboration requires a process or a group of activities that must be defined and developed with the contribution of the partners. Also, the collaboration will follow an innovation process that can be divided into different phases ranging from the generation of ideas/opportunities to the launch of the proposal to the market. The starting stage of the collaboration will depend on the objectives of the partners and the state of progress of the proposal.
- Human relationship and skills (human skills): A collaboration is an initiative that seeks to mix the skills, backgrounds, experiences, and ideas of different people who interact for the benefit of value creation. This interaction can take place either internally (teams, services, etc.) or with other companies. All this must take place in a context favorable to collaboration, characterized by trust, absorption capacity, and openness to the promotion of new ideas, among other factors.

- Organizational: When partners agree to collaborate, people from different functions are involved, coming from different teams and possibly from different geographical locations. To manage this diversity of participants, partners must clearly agree on the tasks and responsibilities of each participant and also have a communication channel that facilitates interactions between actors. In addition, the commitment of the organization's leaders will facilitate the adoption of the collaborative initiative between people and the decision-making process.

- Ecosystem/network: Collaboration seeks resources and skills that are not available. For this reason, a collaboration may involve different actors in an organization's ecosystem: users, suppliers, customers, universities, competitors, government, etc. These actors may be established in the same geographical area, or in other regions or countries. Each of the actors may bring different benefits to the collaboration. For example, universities have specific knowledge and a wide variety of disciplines that facilitate problem solving. The relationship with customers and users can help to identify ideas or unmet needs, while collaboration with suppliers can reduce development times and costs.

Figure 2. Dimensions of the co-innovation process between customer and supplier

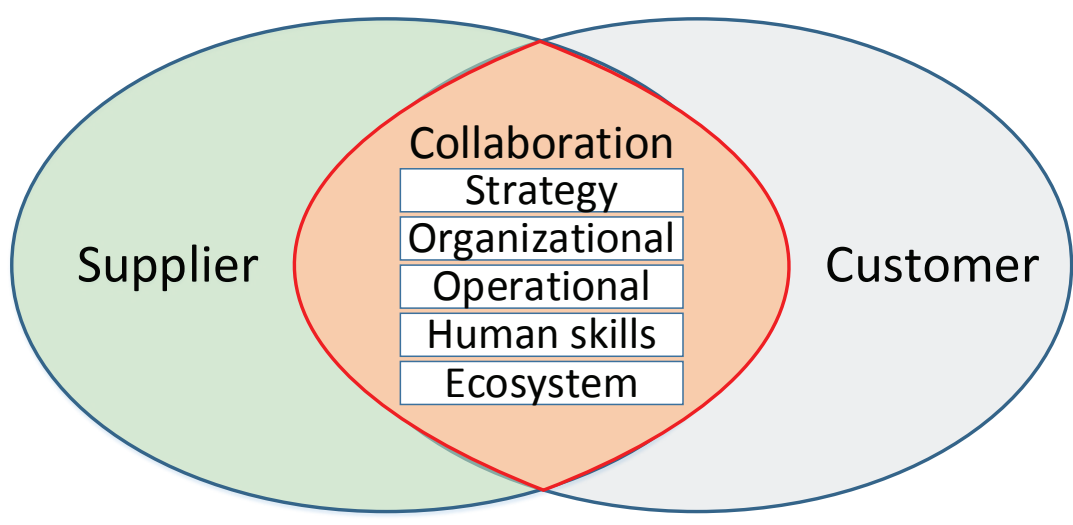

In conclusion, for the evaluation of a customer/supplier co-innovation, it seems pertinent to consider these five common elements or focal points, as given in Figure 2. Each element can be considered a different monitoring point, as each of us regrouped different practices for collaborative process management. Thus each one can be considered to represent a different dimension of the same co-innovation process.

\section{Stage 3: Literature identification of practices associated with the proposed frameworks}

Previous stages are mainly based on the review of ISO, CEN, and AFNOR standards related to open innovation or collaboration. At this stage, a more general literature review is conducted with the aim of identifying and comparing publications that have developed models or frameworks for the study of co-innovation. 
Figure 3. Literature selection process based on (Tran Thi Hoang, Dupont, \& Camargo, 2019) and VOSviewer diagram

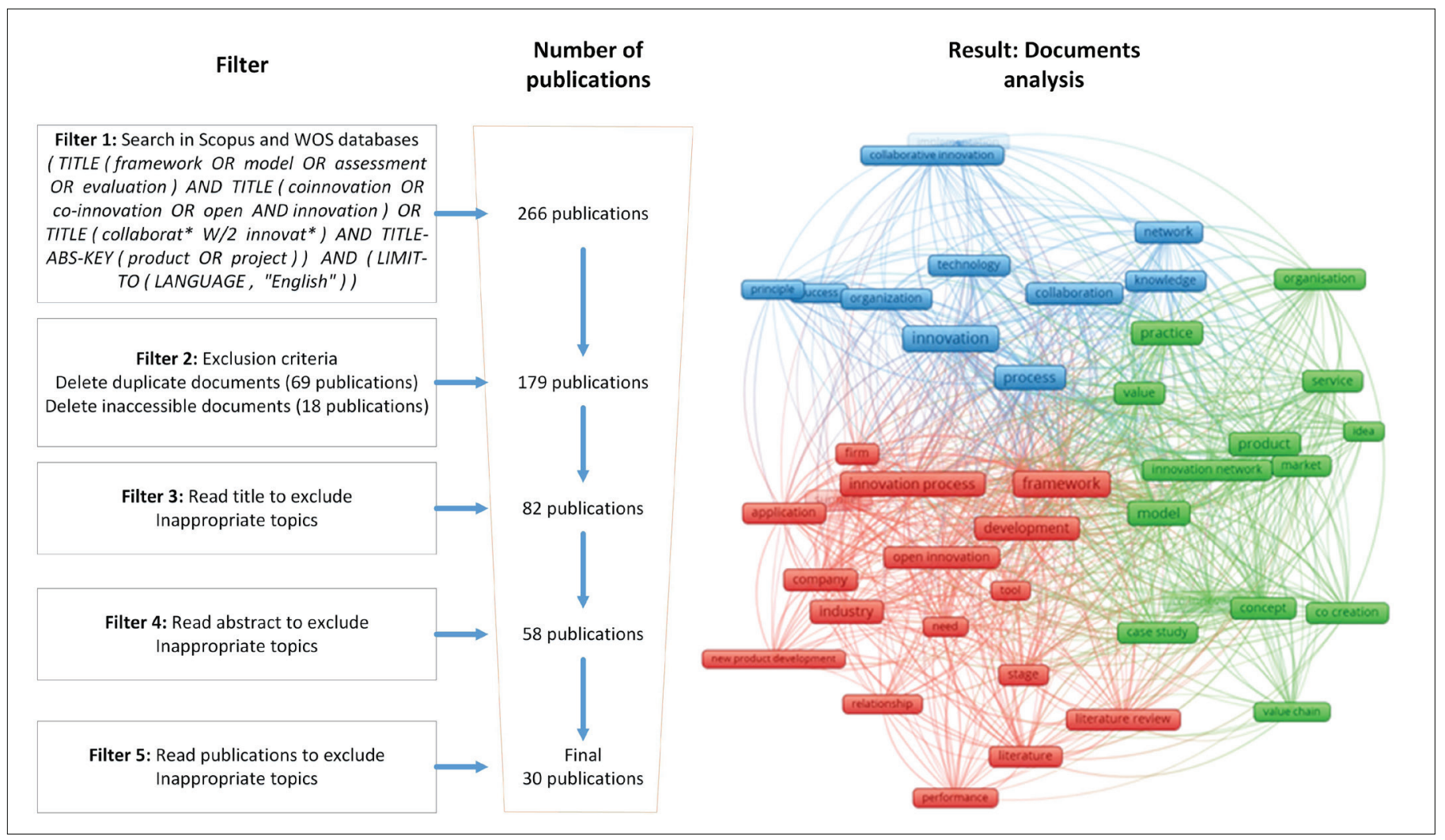

Figure 3 describes the filters used for article selection. Finally, after the five filters applied, 30 documents meet the conditions and are subject to an in-depth analysis. The first analysis is done using VOSviewer because it is open-access bibliometric network visualization software. The objective of the literature review is to identify and compare frameworks or models that address co-innovation. The results of Figure 3 present a diagram of three clusters based on the most frequent words in the abstracts of the publications. Each of the clusters represents a different type of framework or model. The following are some commentaries from articles belonging to each cluster:

- Cluster 1 (green): This cluster represents the frameworks/models focused on the dynamics of idea or concept generation, the early stages of the innovation process, or the co-creation dynamics in an innovation network. Some of the words in this cluster are model (16), concept (9), value (8), innovation network (5), cocreation (5), co-innovation (5), and others.

(Ehlen, van der Klink, Stoffers, \& Boshuizen, 2017) propose a conceptual and practical model consisting of a four-dimensional co-creation wheel. This conceptual model is composed of twelve factors arranged in four dimensions, plus external conditions and a core section. This framework integrates individual, group, and organizational characteristics and behaviors. (Duin, Jaskov, Hesmer, \& Thoben, 2008) presents a conceptual framework that aims to support the innovation process in the early stages through collaborative working environments. Another example is (Hesmer \& Thoben, 2009), who address the initial stages of the innovation process (idea generation), proposing a specific framework for idea generation and the evaluation process based on real user needs. The framework contains three sections: influence, innovation, and knowledge. Also, based on the literature and a case study of the customer-supplier relationship, (Park \& Lee, 2015) propose a framework to analyze the process of co-creating value in the high-tech industry (B-to-B). Four resources (financial, knowledge, efficiency, and intellectual resources) and five competencies (relational, collaborative, strategic, innovation, and management capabilities) were identified. Although this cluster groups works related to the early stages of innovation, most of the documents address the innovation process in a global way.

- $\quad$ Cluster 2 (blue): This cluster groups the models and frameworks focused on knowledge management in the collaborative innovation process within a network of actors. Some of the words in this cluster are innovation (17), process (15), collaboration (7), network (7), knowledge (5), and others.

(Matheis, 2015) presents a work that supports collaborative innovation projects between partners from different industry sectors, and identifies concepts, methods, and tools to improve the control structure regarding the "knowledge" aspect, improving the management of the virtualized assets of the ecosystem. (Lopes \& de Carvalho, 2018) conducted a review of the literature to 
propose a contingency framework for open innovation, composed of background, enablers, constructs, contingent variables, knowledge flow, and performance. (Song, Ming, \& Wang, 2013) propose a framework based on the theory of modularization and seek to reduce the complexity of innovation tasks to increase the ability to complete them in parallel and synergistically. The proposed framework systematically considers both internal and external sources of innovation, and provides specific guidance to reuse and integrate internal and external knowledge. (Wan \& Quan, 2014) describe open innovation in the context of the medical industry and propose a model to examine the exchange and flow of knowledge in the process of open innovation.

- $\quad$ Cluster 3 (red): The last cluster mainly groups the frameworks and models that have the objective of studying the dynamics of new product development (NPD) in companies in a context of open innovation. Some of the words in this cluster are framework (19), innovation process (13), development (11), open innovation (8), new product development (2), and others.

- (Le Dain et al., 2011) present a framework for evaluating supplier performance in collaborative design in the context of a new product development project between client and supplier. Four areas of performance are distinguished: product, process, project, and relationship. (Grönlund et al., 2010) propose an open stage-gate model where each stage can generate input or output. In this model, criteria are added for the evaluation of inbound and outbound transactions. This model helps to continuously adapt the business model and core competencies of the company. (Song, Cao, \& Zheng, 2016) present a framework for the study of an innovation network for the NPD process. It integrates suppliers, customers and innovation intermediaries. Therefore, this framework considers the internal and external actors and the collaborative innovation process for an NPD project.

Note that 50 percent of the documents studied correspond to frameworks, while the other half are models. In addition, the three clusters presented above represent the most frequent documents in the 30 publications studied.

\section{Stage 4: Dimensions and best practices identification to manage collaborative innovation projects}

Although the documents studied do not specifically address collaborative innovation between the customer and supplier but rather consider the supplier to be another actor in the organization's ecosystem, the frameworks and models analyzed can be compared with the five dimensions identified from the standards in order to identify good practices in the customer/supplier collaboration process. The background information gathered is as follows:

- Objectives and strategy definition: Each partner has its own needs, beliefs, and motivations. The partners should therefore collectively discuss and define the objectives of the collaboration (A. Lau, Fischer, Hirsch, \& Matheis, 2012 ; Tan \& Saragih, 2018). They should ensure an alignment between organizational strategies and the innovation strategy (Avans, 2017 ; Hosseini, Kees, Manderscheid, Röglinger, \& Rosemann, 2017) and a diffusion of these decisions throughout the organization (Owen, Goldwasser, Choate, \& Blitz, 2008). Analysis and management of risks in the innovation project is also a major concern (Le Dain et al., 2011).The expected results of the collaboration can be new products, new services, or business models, among other things (Tan \& Saragih, 2018).

Given the dynamic nature of the collaboration, teams should consider revisiting objectives and outcomes, for example, because of external influences (Coutts et al., 2017 ; Knoke, 2015) or because of a change in strategy by one of the partners (Owen et al., 2008).

Regardless of participation in a creative process, partners should keep in mind that resources are limited and decisions need to be made on how to effectively use them (Berasategi, Arana, \& Castellano, 2011). Therefore, it is important to define how resources will be allocated and managed (Knoke, 2015 ; Park \& Lee, 2015).

Open innovation is linked to collaborative methods that contemplate knowledge diffusion. Thus IP management becomes an important issue (Berasategi et al., 2011; Hosseini et al., 2017 ; Knoke, 2015 ; Knoke et al., 2015). The project must have mechanisms or competencies to resolve conflicts over intellectual property (Owen et al., 2008), in addition to establishing how the exploitation or commercialization of technologies and knowledge generated in the project will be carried out (Grönlund et al., 2010).

- Process activities: Regardless of the number of stages of the innovation process or the model used, actors should understand what the potential of each stage is for collaboration and the specific resources they need (Grönlund et al., 2010) in terms of knowledge (Song et al., 2013). Collaboration is an iterative process that involves the exploration, creation, and exploitation of knowledge (Duin et al., 2008).

Working collaboratively means adjusting processes and tools for partners to work together. Therefore, the necessary elements should be considered in order to allow the partners to develop their parallel tasks in a clear, shared, monitored, and integrated process (Berasategi et al., 2011 ; A. Lau et al., 2012). In addition to technical skills, (Hosseini et al., 2017 ; Tan \& Saragih, 2018) state that project management skills should also be considered. Then the project must consider tools that help to manage the daily operations of the development process (Santanna-Filho, Rabelo, Bernus, \& Pereira-Klen, 2016 ; Santanna-Filho, Rabelo, \& Pereira-Klen, 2015). One dimension of management is the monitoring of the participants with respect to the given roles 
(Santanna-Filho et al., 2016) and the performance evaluation of the activities deployed (Berasategi et al., 2011). The objective is to regularly review the state of progress with respect to planning (Coutts et al., 2017). In terms of evaluation, in addition to traditional indicators, indicators appropriate to innovation must be defined (Santanna-Filho et al., 2016, 2015), specific to each stage of the process (Le Dain et al., 2011) and adapted to collaboration (Grönlund et al., 2010).

- Human relationship and skills: Collaboration means creating a favorable working space for collaboration (Ehlen et al., 2017). This concerns actors who have different interests, objectives, and cultural systems that may be conflicting (Coutts et al., 2017 ; Duin et al., 2008 ; Hesmer \& Thoben, 2009 ; Tan \& Saragih, 2018). Therefore, a culture should be encouraged for individuals and teams to promote the generation and sharing of good ideas (Jaafar \& Rezaeian, 2019), acceptance and collective respect to find consensus (Ehlen et al., 2017), flexibility to respond to setbacks (Coutts et al., 2017), and generation of trust, which is a cornerstone (Berasategi et al., 2011 ; Owen et al., 2008 ; Park \& Lee, 2015). In addition to the technical requirements, collaboration also involves soft skills of the participants, such as relational skills (Ehlen et al., 2017 ; Le Dain et al., 2011) and conflict resolution skills (Coutts et al., 2017 ; Owen et al., 2008 ; Park \& Lee, 2015).

Another aspect is the openness of the participants to collaborating and considering ideas that come from outside (Wan \& Quan, 2014), overcoming barriers such as the Not-InventedHere syndrome (Hosseini et al., 2017). Collaboration should capture learning that can be applied in future projects (Owen et al., 2008 ; Park \& Lee, 2015). This implies skills for knowledge absorption, learning management (Park \& Lee, 2015), and knowledge management (Song et al., 2013), for example by creating unique repositories (Knoke, 2015). At the individual level, collaboration should attempt to consider personal preferences and motivations (Ehlen et al., 2017) and the incentive system (Santanna-Filho et al., 2016, 2015).

- Organization: In collaboration, teams are composed of people from different organizations, therefore a clear definition of roles is required (A. Lau et al., 2012). The governance model that will guide coordination and interaction among partners must be established (Berasategi et al., 2011 ; Hosseini et al., 2017 ; Knoke, 2015 ; Owen et al., 2008 ; Santanna-Filho et al., 2015 ; Tan \& Saragih, 2018). This means the rules that will establish how the project will be managed, the roles and responsibilities, the coordination of actors, the boundaries, and the decision-making model (Santanna-Filho et al., 2016). This definition will help in the adoption and implementation of open innovation activities (Hosseini et al., 2017). In addition, the type of configuration to be used during the project must be defined, for example, if it is a virtual company or another type (Romero \& Molina, 2011).

The collaboration should establish interaction channels between partners (Romero \& Molina, 2011) and transparent communication between team participants (Ehlen et al., 2017). In contrast to traditional innovation, partners should consider meetings and information exchange between people in different geographical locations (A. Lau et al., 2012). In addition, teams should be composed not only of R\&D personnel but of all organizational functions (Berasategi et al., 2011) and with the support and commitment of managers (Ehlen et al., 2017 ; Hosseini et al., 2017).

- Ecosystem/network: : Collaboration is a pattern increasingly used in innovation and is based on interaction with different actors, each having its own ecosystem (Lopes \& de Carvalho, 2018). Therefore, the influence of each external actor on the innovation project should be studied (Duin et al., 2008 ; Tan \& Saragih, 2018). There are influences coming from the direct ecosystem that impact the generation of ideas and/or the search for innovative products (Remi Maniak \& Midler, 2008), while other influences come from the political, sociocultural, technological, and legislative context (Hesmer \& Thoben, 2009).

In conclusion, the interaction and monitoring of external networks is necessary to find new ideas and products and to avoid developing things that have been done before (Grönlund et al., 2010). This monitoring can even include the ecosystem of the project partner (Avans, 2017). Although the collaborative project is between a group of partners, this does not preclude a wider context of actors (Berasategi et al., 2011 ; Park \& Lee, 2015).

\section{Stage 5: Characterization model of customer-supplier col- laboration in an innovation project}

Based on a review of customer/supplier co-innovation literature, a review of standards, and a review of co-innovation publications, it is possible to conclude that customer/supplier co-innovation can be represented as the temporary union of two companies around an innovation project. This union generates a common space where resources, activities, and outcomes are shared. Thus, as Table 1 shows, the common space can be described from the above dimensions, involving different tasks and practices. Each of these dimensions represents a different view of the process and contains the collaborative space formed by both organizations working together. 
Table 1. Customer/supplier co-innovation: Five dimensions

\begin{tabular}{lll}
\hline Dimensions & $\begin{array}{l}\text { Collaboration } \\
\text { implies... }\end{array}$ & $\begin{array}{l}\text { The common space } \\
\text { between the partners is } \\
\text { described by: }\end{array}$ \\
\hline
\end{tabular}

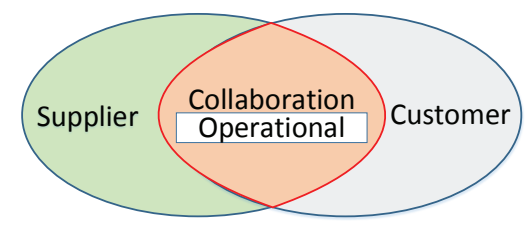

creating/implementing collaborative development activities

all the tasks required to achieve the objectives of the collaboration

Project monitoring: To know the progress of the project (tasks done within the two companies) in relation to the planning and to be able to carry out the necessary corrective actions.

Availability, sharing, and quality of information: Given the diversity of actors, the content and form of information should be adapted to facilitate exchange.

Tools for the collaborative process: Depending on several characteristics of the collaboration, the methodological requirements may be more or less complicated. At each stage of the project, various methodologies must be chosen and implemented.

Clear definition of tasks, roles, and responsibilities: Clear definitions of roles and responsibilities assigned to each of the partners.

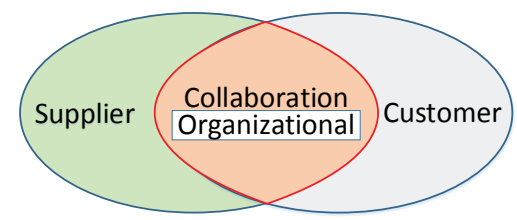

identifying the services and human resources involved in the collaboration temporary collaborative space that includes the services and human resources involved in the collaboration

Governance and Leadership: Decision-making mandates and processes for achieving consensus among partners must be clearly identified.

Internal communication: Implementation and monitoring of communication channels and contents between the members of a project

Multi-level and multidisciplinary team: Teams defined with members from different functions and companies

Collaboration objectives and aligned strategy: The process of collaboration requires a concerted strategy that defines common and shared objectives.

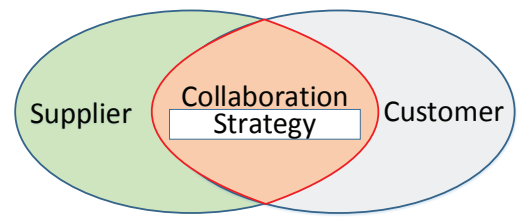

defining the objectives of the collaboration common strategy including the objectives of the collaboration space all the skills required to developing the necessary skills for collaboration increase the chances of successful collaborative innovation

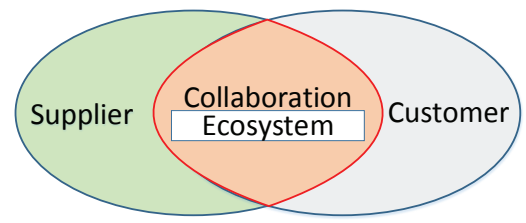

structuring the ecosystem that will enable collaboration to be implemented a common ecosystem that includes external actors who will contribute to the design and implementation of the product.
Value distribution: The goal of collaboration is to generate value, therefore companies must agree on how the value generated in the process will be distributed.

Resources allocation: Partners should consider allocating the human, material, and financial resources necessary for the collaboration.

IP management: Protection of the results of the collaboration is defined, whether in the form of confidentiality agreements, patents, etc.

Absorption and learning capacity: Team members must be able to collect and integrate knowledge from outside and/or other team members into the project. Knowledge and procedures generated during the innovation project must be capitalized for use in future projects or in the event of staff changes.

Conflict resolution: The aim of change management is to promote the assimilation of the novelty induced by the development of the innovation project in both companies.

Create favorable conditions: The motivation and commitment of each of the project participants will promote the achievement of objectives and the progress of the project.

Technical skills: Knowing and being able to use the different tools and methods necessary to conduct the collaborative project will allow one to progress in the different development activities and to reduce the associated delays and costs.

Ecosystem intelligence: Signals from outside are taken into account, such as market developments, the emergence of new technologies, and trends.

External communication: Partners develop communication tools and actions to publicize the collaboration and/or the project, find resources, and anchor the project in its environment (political, industrial, social).

Future partners: The future joint product will have a support supply chain that the partners must consider, study, design, better structure through contacts, and implement. 


\section{Conclusions}

Based on a review of the literature on customer-supplier collaborative innovation, a review of international standards on open innovation or collaboration, and a review of scientific publications on co-innovation frameworks and models, this document identifies five dimensions and 18 practices of the customer-supplier collaborative innovation process. The five dimensions identified characterize the customer/supplier innovation process. Through the practices, the five identified dimensions may be instantiated. Each innovation is characterized by the practices achieved by people involved in the process. The model at this stage is still theoretical and further validation is required through its application in various case studies. Among others situations to be tested are the collaboration between big companies and start-ups, private and public partnership, sectors where patenting is important or not (i.e. agroindustry). The proposed dimensions and practices define the temporary common space of activity between the partners. This space duration corresponds to the common project between partners. There are some questions still to be addressed, in particular the question of the dynamic of the collaboration, because the way people achieve the practices is highly evolving during the project. Finally, one major perspective concerns the evaluation of the practices. One possibility is to propose a set maturity grids representing the degree of development for each practice and an aggregation method to assess the global maturity of the collaborative space.

As a perspective, this document is part of an investigation that seeks to create and/or improve the dynamics of collaboration between the customer and supplier in the context of an innovation project. The research aims to develop a management tool based on the evaluation of good practices, which helps partners manage a collaborative innovation process. Therefore, based on the results of this document, the next step is to validate with experts the list of identified practices and to define the method of evaluation.

\section{Acknowledgements}

This research is one of the projects of the Lab PEAK by Thèsame, in order to promote collaborative innovation between customers and suppliers. The authors would like to thank the support of Thèsame, the Union of Metal Industries and Professions UIMM (Innovation and Industry Fund F2I), the Auvergne-Rhône-Alpes Region and the "Filière Automobile et Mobilité PFA" (PIA ACE project, Fonds Caisse des Dépôts).

\section{References}

AFNOR. (2019). FD X50-272 Management of innovation - Guidelines for the implementation of the open innovation approach.

Avans, F. S. (2017). The Co-Innovation Alliance Scan, Tool for Effective Collaboration with External Partners. Journal on Innovation and Sustainability. RISUS ISSN 2179-3565, 8(2), 170. https://doi. org/10.24212/2179-3565.2017v8i2p170-179

Bengtsson, L., Lakemond, N., \& Dabhilkar, M. (2013). Exploiting supplier innovativeness through knowledge integration. International Journal of Technology Management, 61(3/4), 237. https://doi. org/10.1504/IJTM.2013.052669
Berasategi, L., Arana, J., \& Castellano, E. (2011). A comprehensive framework for collaborative networked innovation. Production Planning and Control, 22(5-6), 581-593. https://doi.org/10.1080/0953728 7.2010 .536628

Bhaskaran, S. R., \& Krishnan, V. (2009). Effort, Revenue, and Cost Sharing Mechanisms for Collaborative New Product Development. Management Science, 55(7), 1152-1169. https://doi.org/10.1287/ mnsc. 1090.1010

Boly, V., Camargo, M., \& Morel, L. (2016). Ingénierie de l'innovation (3è édition). (S.l.) : Hermes Science Publications.

CEN. (2014). XP CEN/TS 16555-5 Management de l'innovation Partie 5 : Management de la collaboration.

Chesbrough, H., \& Bogers, M. (2014). Explicating Open Innovation: Clarifying an Emerging Paradigm for Understanding Innovation Keywords. New Frontiers in Open Innovation. https://doi.org/10.1093/acprof

Chesbrough, H W. (2003). Open Innovation: The New Imperative for Creating and Profiting from Technology. (S.1.): Harvard Business School Press. Repéré à https://books.google.fr/books?id=4hTRWStFhVgC

Chesbrough, Henry William. (2006). Open innovation: The new imperative for creating and profiting from technology. Boston, Massachussetts : Harvard Business Press.

Clauß, T. (2012). The Influence of the Type of Relationship on the Generation of Innovations in Buyer-Supplier Collaborations. Creativity and Innovation Management, 21(4), 388-411. https://doi.org/10.1111/ j.1467-8691.2012.00651.x

Coutts, J., White, T., Blackett, P., Rijswijk, K., Bewsell, D., Park, N., ... Botha, N. (2017). Evaluating a space for co-innovation: Practical application of nine principles for co-innovation in five innovation projects. Outlook on Agriculture, 46(2), 99-107. https://doi. org/10.1177/0030727017708453

de Paulo, A. F., De Oliveira, S. V. W. B., \& Porto, G. S. (2017). Mapping impacts of open innovation practices in a firm competitiveness.: University of Liverpool Library. Technology Management \& Innovation, 12(3), 108-118. Repéré à http://eds.b.ebscohost.com.liverpool.idm. oclc.org/eds/pdfviewer/pdfviewer?vid=1\&sid=b21eb9c2-c617-476f9352-b72f41a5e2d8\%40sessionmgr101

de Soria, I. M., Alonso, J., Orue-Echevarria, L., \& Vergara, M. (2009). Developing an enterprise collaboration maturity model: Research challenges and future directions. Dans 2009 IEEE International Technology Management Conference (ICE) (pp. 1-8). IEEE. https://doi. org/10.1109/ITMC.2009.7461411

Duin, H., Jaskov, J., Hesmer, A., \& Thoben, K.-D. (2008). Towards a Framework for Collaborative Innovation. Dans Computer-Aided Innovation (CAI) (Vol. 277, pp. 193-204). Boston, MA : Springer US. https://doi.org/10.1007/978-0-387-09697-1_16 
Dung, L. T. (2015). Factors Affecting the Collaboration in Supply Chain of Mechanical Enterprises in Vietnam. International Journal of Managing Value and Supply Chains, 6(4), 17-29. https://doi. org/10.5121/ijmvsc.2015.6402

Ehlen, C., van der Klink, M., Stoffers, J., \& Boshuizen, H. (2017). The Co-Creation-Wheel. European Journal of Training and Development, 41(7), 628-646. https://doi.org/10.1108/EJTD-03-2017-0027

Fielke, S. J., Botha, N., Reid, J., Gray, D., Blackett, P., Park, N., \& Williams, T. (2018). Lessons for co-innovation in agricultural innovation systems: a multiple case study analysis and a conceptual model. Journal of Agricultural Education and Extension, 24(1), 9-27. https://doi. org/10.1080/1389224X.2017.1394885

Fossas-olalla, M., Lopez-sanchez, J. I., \& Minguela-rata, B. (2010). Cooperation with suppliers as a source of innovation. African Journal of Business Management, 4(16), 3491-3499.

Greco, M., Grimaldi, M., \& Cricelli, L. (2019). Benefits and costs of open innovation: the BeCO framework. Technology Analysis \& Strategic Management, 31(1), 53-66. https://doi.org/10.1080/09537325.2 018.1484442

Grönlund, J., Sjödin, D. R., \& Frishammar, J. (2010). Open innovation and the stage-gate process: A revised model for new product development. California Management Review, 52(3), 106-131. https://doi. org/10.1525/cmr.2010.52.3.106

Hasche, N., Linton, G., \& Öberg, C. (2017). Trust in open innovation - the case of a med-tech start-up. European Journal of Innovation Management, 20(1), 31-49. https://doi.org/10.1108/EJIM-10-2015-0111

Herzog, P., \& Leker, J. (2010). Open and closed innovation - different innovation cultures for different strategies. International Journal of Technology Management, 52(3/4), 322. https://doi.org/10.1504/ IJTM.2010.035979

Hesmer, A., \& Thoben, K.-D. (2009). Framework and IT-based toolset to support the early stages of collaborative innovation. Dans 2009 IEEE International Technology Management Conference (ICE) (pp. 1-14). IEEE. https://doi.org/10.1109/ITMC.2009.7461375

Hosseini, S., Kees, A., Manderscheid, J., Röglinger, M., \& Rosemann, M. (2017). What does it take to implement open innovation? Towards an integrated capability framework. Business Process Management Journal, 23(1), 87-107. https://doi.org/10.1108/BPMJ-03-2016-0066

Hudnurkar, M., Jakhar, S., \& Rathod, U. (2014). Factors affecting collaboration in supply chain : A literature Review. Procedia - Social and Behavioral Sciences, 133, 189-202. https://doi.org/10.1016/j.sbspro.2014.04.184

ISO. (2019). INTERNATIONAL STANDARD ISO 56002: Innovation management - Innovation management system - Guidance, ISO56002:2.
Jaafar, M. A., \& Rezaeian, A. (2019). Envisioning multi-level open innovation process: toward a framework. Religacion. Journal Of Social Sciences and Humanities, 4(15), 86-104. https://doi.org/10.1088/1751$8113 / 44 / 8 / 085201$

Knoke, B. (2015). The BIVEE Framework and the Collaborative Innovation Capability Maturity Model (CICMM). Dans Enterprise Innovation (pp. 91-110). Hoboken, NJ, USA : John Wiley \& Sons, Inc. https://doi.org/10.1002/9781119145622.ch6

Knoke, B., Missikoff, M., \& Thoben, K.-D. (2015). Collaborative open innovation management in virtual manufacturing enterprises. International Journal of Computer Integrated Manufacturing, 30(1), 1-9. https://doi.org/10.1080/0951192X.2015.1107913

Kwon, I. G., Louis, S., \& Louis, S. (2004). Factors Affecting the Level of Trust and Commitment in, 4-14.

Lau, A., Fischer, T., Hirsch, M., \& Matheis, H. (2012). SmartNet collaboration model - a framework for collaborative development and production. Dans 2012 18th International ICE Conference on Engineering, Technology and Innovation (pp. 1-10). IEEE. https://doi. org/10.1109/ICE.2012.6297687

Lau, A. K. W., Lee, L. W. Y., Lai, K.-H., \& Lee, P. K. C. (2018). Adopting an Open Innovation Program with Supply Chain Management in China: A Case Study. Engineering Management Journal, 30(1), 24-41. https://doi.org/10.1080/10429247.2017.1408387

Laursen, L. N., \& Andersen, P. H. (2016). Supplier involvement in NPD: A quasi-experiment at Unilever. Industrial Marketing Management, 58, 162-171. https://doi.org/10.1016/j.indmarman.2016.05.023

Lavastre, O., Carbone, V., \& Ageron, B. (2016). Les grands auteurs en logistique et Supply Chain Management. (S.l.) : (s.n.).

Le Dain, M.-A., Calvi, R., \& Cheriti, S. (2011). Measuring supplier performance in collaborative design: proposition of a framework. R\&D Management, 41(1), 61-79. https://doi.org/10.1111/j.14679310.2010.00630.x

Legenvre, H., \& Gualandris, J. (2018). Innovation sourcing excellence: Three purchasing capabilities for success. Business Horizons, 61(1), 95-106. https://doi.org/10.1016/j.bushor.2017.09.009

Littler, D., Leverick, F., \& Bruce, M. (1995). Factors Affecting the Process of Collaborative Product Development: A Study of UK Manufacturers of Information and Communications Technology Products. Journal of Product Innovation Management, 12(1), 16-32. https://doi. org/10.1111/1540-5885.1210016

Lopes, A. P. V. B. V., \& de Carvalho, M. M. (2018). Evolution of the open innovation paradigm: Towards a contingent conceptual model. Technological Forecasting and Social Change, 132(February), 284-298. https://doi.org/10.1016/j.techfore.2018.02.014 
Luzzini, D., Amann, M., Caniato, F., Essig, M., \& Ronchi, S. (2015). The path of innovation: purchasing and supplier involvement into new product development. Industrial Marketing Management, 47, 109-120. https://doi.org/10.1016/j.indmarman.2015.02.034

Maier, M. A., Rück, P., \& Brem, A. (2017). How to Integrate Suppliers into the Innovation Process? An Explorative Case of Champion Formalization in the Purchasing Department in Times of Open Innovation. International Journal of Innovation and Technology Management, 14(06), 1750036. https://doi.org/10.1142/S0219877017500365

Maniak, Remi, \& Midler, C. (2008). Shifting from co-development to co-innovation. International Journal of Automotive Technology and Management, 8(4), 449. https://doi.org/10.1504/IJATM.2008.020313

Maniak, Rémi, Midler, C., Beaume, R., \& von Pechmann, F. (2014). Featuring Capability: How Carmakers Organize to Deploy Innovative Features across Products. Journal of Product Innovation Management, 31(1), 114-127. https://doi.org/10.1111/jpim.12083

Matheis, H. (2015). Model-based control for collaborative Innovation Projects. International Conference on Engineering, Technology and Innovation/ International Technology Management Conference, ICE/ ITMC 2015, (262806).

Melander, L. (2018). Customer and Supplier Collaboration in Green Product Innovation: External and Internal Capabilities. Business Strategy and the Environment. https://doi.org/10.1002/bse.2024

OECD. (2019). Oslo Manual 2018. Handbook of Innovation Indicators and Measurement. (S.l.) : OECD. https://doi. org/10.1787/9789264304604-en

Owen, L., Goldwasser, C., Choate, K., \& Blitz, A. (2008). Collaborative innovation throughout the extended enterprise. Strategy \& Leadership, 36(1), 39-45. https://doi.org/10.1108/10878570810840689

Park, C., \& Lee, H. (2015). Value Co-Creation Processes-Early Stages of Value Chains Involving High-Tech Business Markets: Samsung-Qualcomm Semiconductor Foundry Businesses. Journal of Business-to-Business Marketing, 22(3), 229-252. https://doi.org/10.10 80/1051712X.2015.1081016

Patrucco, A. S., Luzzini, D., \& Ronchi, S. (2017). Achieving innovation through supplier collaboration: the role of the purchasing interface. Business Process Management Journal, 23(6), 1270-1289. https:// doi.org/10.1108/BPMJ-10-2016-0202

Pihlajamaa, M., Kaipia, R., Säilä, J., \& Tanskanen, K. (2017). Can supplier innovations substitute for internal R\&D? A multiple case study from an absorptive capacity perspective. Journal of Purchasing and Supply Management, 23(4), 242-255. https://doi.org/10.1016/j.pursup.2017.08.002

Radziwon, A., \& Bogers, M. (2019). Open innovation in SMEs: Exploring inter-organizational relationships in an ecosystem. Technological Forecasting and Social Change, 146(April), 573-587. https://doi. org/10.1016/j.techfore.2018.04.021
Ragatz, G. L., Handfield, R. B., \& Scannell, T. V. (2003). Success Factors for Integrating Suppliers into New Product Development. Journal of Product Innovation Management, 14(3), 190-202. https://doi. org/10.1111/1540-5885.1430190

Ragatz, G. L., Handfield, R. B., \& Scannell, T. V. (1997). Success Factors for Integrating Supplier into New Product Development. Journal of Product Innovation Management. https://doi.org/10.1016/S07376782(97)00007-6

Romero, D., \& Molina, A. (2011). Collaborative networked organisations and customer communities: value co-creation and co-innovation in the networking era. Production Planning \& Control, 22(5-6), 447-472. https://doi.org/10.1080/09537287.2010.536619

Rosell, D. T., \& Lakemond, N. (2012). Collaborative innovation with suppliers: a conceptual model for characterising supplier contributions to NPD. International Journal of Technology Intelligence and Planning, 8(2), 197. https://doi.org/10.1504/IJTIP.2012.048477

Santanna-Filho, J. F., Rabelo, R. J., Bernus, P., \& Pereira-Klen, A. A. (2016). Improving the Sustainability of SOA Providers' Networks via a Collaborative Process Innovation Model. Dans IFIP Advances in Information and Communication Technology (Vol. 488, pp. 511-519). (S.l.) : (s.n.). https://doi.org/10.1007/978-3-319-51133-7_61

Santanna-Filho, J. F., Rabelo, R. J., \& Pereira-Klen, A. A. (2015). A Flexible Collaborative Innovation Model for SOA Services Providers (pp. 366-376). (S.l.) : (s.n.). https://doi.org/10.1007/978-3-319-24141-8_33

Sariola, R. (2018). Utilizing the innovation potential of suppliers in construction projects. Construction Innovation, CI-06-2017-0050. https://doi.org/10.1108/CI-06-2017-0050

Schiele, H. (2010). Early supplier integration: the dual role of purchasing in new product development. R\&D Management, 40(2), 138-153. https://doi.org/10.1111/j.1467-9310.2010.00602.x

Schiele, H., Veldman, J., \& Hûttinger, L. (2011). Supplier Innovativeness and Supplier Pricing: The Role of Preferred Customer Status. International Journal of Innovation Management, 15(01), 1-27. https:// doi.org/10.1142/S1363919611003064

Servajean-Hilst, R., \& Calvi, R. (2018). SHADES OF THE INNOVATION-PURCHASING FUNCTION - THE MISSING LINK OF OPEN INNOVATION. International Journal of Innovation Management, 22(01), 1850008. https://doi.org/10.1142/S1363919618500081

Sjoerdsma, M., \& van Weele, A. J. (2015). Managing supplier relationships in a new product development context. Journal of Purchasing and Supply Management, 21(3), 192-203. https://doi.org/10.1016/j. pursup.2015.05.002

Song, W., Cao, J., \& Zheng, M. (2016). Towards an integrative framework of innovation network for new product development project. Production Planning \& Control, 27(12), 967-978. https://doi.org/10.10 80/09537287.2016.1167980 
Song, W., Ming, X., \& Wang, P. (2013). Collaborative product innovation network: Status review, framework, and technology solutions. Concurrent Engineering, 21(1), 55-64. https://doi. org/10.1177/1063293X12468457

Soosay, C. A., Hyland, P. W., \& Ferrer, M. (2008). Supply chain collaboration: capabilities for continuous innovation. Supply Chain Management: An International Journal, 13(2), 160-169. https://doi. org/10.1108/13598540810860994

Su, Q., Song, Y. tao, Li, Z., \& Dang, J. xiang. (2008). The impact of supply chain relationship quality on cooperative strategy. Journal of Purchasing and Supply Management, 14(4), 263-272. https://doi. org/10.1016/j.pursup.2008.08.002

Tan, J. D., \& Saragih, H. S. (2018). Co-innovation: a review and conceptual framework. International Journal of Business Innovation and Research, 17(3), 361. https://doi.org/10.1504/IJBIR.2018.10016527

Tello Gamarra, J., Machado Leo, R., Silva Avila, A. M., \& Wendland, J. (2018). Innovation studies in Latin America: a bibliometric analysis. Journal of technology management \& innovation, 13(4), 24-36. https:// doi.org/10.4067/S0718-27242018000400024

Tran Thi Hoang, G., Dupont, L., \& Camargo, M. (2019). Application of Decision-Making Methods in Smart City Projects: A Systematic Literature Review. Smart Cities, 2(3), 433-452. https://doi.org/10.3390/ smartcities 2030027

Un, C. A. (2017). Absorptive capacity and R\&amp;D outsourcing. Journal of Engineering and Technology Management, 43, 34-47. https://doi.org/10.1016/j.jengtecman.2017.01.001
Vega-Jurado, J. M., Juliao-Esparragoza, D., Paternina-Arboleda, C. D., \& Velez, M. C. (2015). Integrating technology, management and marketing innovation through open innovation models. Journal of Technology Management and Innovation, 10(4), 85-90. https://doi. org/10.4067/S0718-27242015000400009

Wan, H.-H., \& Quan, X. I. (2014). Toward a Framework of the Process of Open Innovation - Case of Acclarent in the Medical Device Industry. International Journal of Innovation and Technology Management, 11(05), 1450032. https://doi.org/10.1142/S0219877014500321

Wang, L., \& Kourouklis, A. (2012). On the Development of a Theoretical Framework for New Product Development. Dans Proceedings of the International Conference on Knowledge Management and Information Sharing (pp. 49-59). SciTePress - Science and and Technology Publications. https://doi.org/10.5220/0004136400490059

Wynstra, F., \& Pierick, E. ten. (2000). Managing supplier involvement in new product development: a portfolio approach. European Journal of Purchasing \& Supply Management, 6(1), 49-57. https://doi. org/10.1016/S0969-7012(99)00035-0

Zhang, X. (2016). The Evaluation Method and Empirical Study on Capability of Customer Collaborative Product Innovation, (Icemc). https://doi.org/10.2991/icemc-16.2016.22

Zhang, Y., Wang, L., \& Gao, J. (2017). Supplier collaboration and speed-to-market of new products: the mediating and moderating effects. Journal of Intelligent Manufacturing, 28(3), 805-818. https:// doi.org/10.1007/s10845-014-1021-5 
